\title{
Prevalence, distribution, and molecular characterization of Salmonella recovered from swine finishing herds and a slaughter facility in Santa Catarina, Brazil
}

\author{
Jalusa D. Kich ${ }^{\text {a,*}}$, Arlei Coldebella ${ }^{a}$, Nelson Morés ${ }^{a}$, Mariana Gomes Nogueira ${ }^{\text {, }}$, Marisa Cardoso ${ }^{\text {b }}$ \\ Pina M. Fratamico ${ }^{\mathrm{c}}$, Jeffrey E. Call ${ }^{\mathrm{c}}$, Paula Fedorka-Cray ${ }^{\mathrm{d}}$, John B. Luchansky ${ }^{\mathrm{c}}$ \\ a Embrapa Suínos e Aves, Caixa Postal: 21, CEP: 89700-000, Concórdia-SC, Brazil

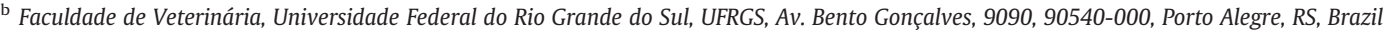 \\ ' USDA, Agricultural Research Service, Eastern Regional Research Center, 600 E. Mermaid Lane, Wyndmoor, PA, USA \\ ${ }^{d}$ USDA, Agricultural Research Service, Richard B. Russell Agriculture Research Center, 950 Station Road, Athens, GA, USA
}

\section{A R T I C L E I N F O}

\section{Article history:}

Received 10 June 2011

Received in revised form 14 September 2011

Accepted 24 September 2011

Available online 1 October 2011

\section{Keywords:}

Salmonella

Swine

PFGE

Resistance

Epidemiology

\begin{abstract}
A B S T R A C T
Swine can carry Salmonella strains that may be transmitted to humans by pork products. This investigation determined the distribution and types of Salmonella in 12 swine finishing herds and a slaughter facility in Santa Catarina, Brazil. A total of 1258 samples, consisting of environmental, feed, carcass, lymph node, and fecal material were collected and submitted to bacteriological isolation of Salmonella. From 487 positive samples, 1255 isolates were recovered and confirmed to be Salmonella. The distribution of positive samples was as follows: finishing pen floors 26\% (16/61); feed 29\% (42/143); feces 44\% (52/119); pooled feces 59\% (35/59); slaughter holding pens $90 \%$ (36/40); lymph nodes 46\% (220/478); pre-chilled carcass surfaces $24 \%$ (24/98); and postchilled carcass surfaces 24\% (62/260). The most prevalent serovars were Typhimurium, Panama, Senftenberg, Derby, and Mbandaka. By pulsed-field gel electrophoresis, 1071 isolates were subtyped using Xbal, and duplicate isolates were removed. From the remaining 747 isolates, 163 macrorestriction profiles (pulsotypes) were identified. Six pulsotypes were considered very frequent, occurring in 33 isolates or more. The multiple correspondence analyses showed correlations between pulsotypes from shedding pigs (feces), herd environment (pen floors), and subiliac and prescapular lymph nodes and between lairage and carcass surface samples before and after chilling. All sources of Salmonella investigated contributed to the carrier state; however, preslaughter contamination at lairage was the variable most strongly associated with carcass contamination. A total of 59 different antimicrobial resistance profiles were observed in 572 Salmonella isolates. From these isolates, 17\% (97/572) were susceptible to all 15 antibiotics tested, 83\% (475/572) were resistant to at least one, and $43 \%$ (246/572) were resistant to four or more antibiotics (multi-resistant). The AmpGenKanTet profile was the most prevalent in carcass isolates and was associated with farm origin.
\end{abstract}

(C) 2011 Elsevier B.V. All rights reserved.

\section{Introduction}

Most Salmonella serotypes are considered potential human pathogens (WHO, 2005), and Salmonella is recognized worldwide as a major human food-borne pathogen (CDC, 2008). Although eggs are considered an important vehicle of infection and associated with food-borne outbreaks, contaminated pork and pork products may be responsible for up to $25 \%$ of all Salmonella infections in humans (Borch et al., 1996). Swine was a primary source of human salmonellosis in $15 \%$ of the cases in Denmark and The Netherlands and $25 \%$ of the cases in the U.S. (Bean and Griffin, 1990).

\footnotetext{
* Corresponding author. Tel.: + 5549 34410400; fax: + 554934410497. E-mail address: jalusa@cnpsa.embrapa.br (J.D. Kich).
}

The continuous entrance of animals carrying and shedding Salmonella in slaughterhouses is the main source of pork contamination (Berends et al., 1997). Thus, efforts have been taken to minimize Salmonella shedding in swine in order to lower the hazard of contamination at slaughterhouses. Good Manufacturing Practices reduce crosscontamination during slaughter and processing; however, the first critical control point involves the reduction of delivery of shedders to the slaughterhouse (Borch et al., 1996). In previous studies, the finishing stage was shown to be critical for Salmonella infection amplification in the swine production system (Funk et al., 2001; Silva et al., 2006). The spread of Salmonella from a number of sources and the variability in the serovars isolated from positive samples demonstrate the epidemiological complexity in the swine production chain. Thus, it is difficult to determine the epidemiological relationship between sources of Salmonella transmission throughout the production chain and pork contamination. There are several tools available for subtyping and discriminating Salmonella, and one commonly-used technique for this 
purpose is DNA macro-restriction associated with pulsed-field gel electrophoresis (PFGE). This method has been used routinely in food-borne outbreak investigations, as well as in epidemiological veterinary studies (CDC, 2004; Giovannacci et al., 2001; Wonderling et al., 2003; Botteldoorn et al., 2004; Vieira-Pinto et al., 2006; Vigo et al., 2009).

Another challenge for human health is the emergence of multidrug resistant Salmonella strains (Duijkeren et al., 2003). Moreover, it has been demonstrated that the transmission of resistance genes among bacteria colonizing the human gut is possible (Trobos et al., 2008). Infection with multi-resistant strains limits the chances of effective treatment. Swine and other production animals are recognized as a primary reservoir of multi-resistant bacteria (Wedel et al., 2005). The emergence of multi-resistant Salmonella is often related to mobile genetic elements (Butaye et al., 2006) that have spreading capacity among the population.

The southern region of Brazil includes the most important swine producing areas in the country, accounting for almost $65 \%$ in the last trimester of 2010 (IBGE, 2011-http://www.ibge.gov.br/home/ estatistica/indicadores/agropecuaria/producaoagropecuaria/abate-leitecouro-ovos_201004_publ_completa.pdf) of the national pork production, which reached 3.19 million tons in 2009 (ABIPECS, 2010). Salmonella infection in swine herds of southern Brazil has been demonstrated by isolation and serology surveys (Kich et al., 2007). Antimicrobial resistance among porcine Salmonella strains has been also reported and characterized (Michael et al., 2005a, 2005b, 2008). In Brazil, ongoing Salmonella surveillance programs are conducted in poultry and interventions have recently been started in pig herds.

The objectives of this study were to determine: (1) the distribution of serotypes and clonal groups of Salmonella in 12 swine finishing herds and a slaughter facility in Santa Catarina, Brazil; (2) the epidemiological relationship among Salmonella isolates from the herd environment (floor swabs), shedders (swine fecal samples), feed, the lairage environment, lymph nodes, and carcasses; and (3) antimicrobial resistance profiles and their relationship with clonal groups and origin of the strains.

\section{Materials and methods}

This longitudinal study was conducted in one swine Production Company that adopted a two-site pig management system in vertically integrated farms. This company represented $7 \%$ of the annual number of pigs slaughtered in Brazil in 2007 (ABIPECS, 2007 http://www.abipecs.org.br/uploads/relatorios/relatorios-associados/ ABIPECS_relatorio_2007_pt.pdf). A total of 12 cohorts represented by finishing herds located in the state of Santa Catarina, Brazil, each with a holding capacity of 250 to 800 animals were included in the study. Pigs in each herd originated from four different piglet production sites. Slaughter-age pigs were delivered to one slaughter facility belonging to the same company.

\subsection{Sampling}

A total of 1258 samples were collected from 12 herds and from the slaughterhouse facility. Samples were collected over the 80-day finishing period from floor pens (61), feces (119), pooled feces (59) and feed (143) from each of the 12 herds. At the end of the 80-day-period, samples from the lairage (40), pre-chill carcasses (98), post-chill carcasses (260), and lymph nodes (478) were collected at the slaughter facility for each lot. To determine the prevalence of Salmonella-positive lymph nodes and carcasses, the population size, an estimated prevalence of $50 \%$, a level of confidence of $95 \%$, and an accepted error of $15 \%$ were taken into account to calculate the sample size (Blas et al., 2007).

\subsubsection{Sampling on placement day}

Before the pigs were placed in the finishing farms, five floor swabs were taken from previously cleaned and disinfected pens to determine residual Salmonella contamination. On the day of placement of the 65-day-old pigs in the farms, fecal samples from 10 individual pigs and five fecal pools (each one from five pigs) were taken to detect Salmonella-shedders. Blood samples were taken from an average of 38 pigs (ranging from 20 to 43 ) in each herd to determine Salmonella seroprevalence.

\subsubsection{Feed sampling}

All herds received pelleted feed from the same manufacturer. Each feed batch delivered to the farms was tested. Using disposable gloves, approximately $500 \mathrm{~g}$ of pelleted feed from at least five mixed portions were collected as the feed was transferred from the truck to the storage bins.

\subsubsection{Pre-slaughter testing}

One day before the transport of the 150-day-old pigs to the slaughterhouse, 24 pigs from each herd were tattooed, and blood samples were collected by puncture of the anterior vena cava to determine Salmonella seroprevalence.

\subsubsection{Slaughterhouse testing}

Three floor swabs were taken from cleaned and disinfected lairage prior to the arrival of the pigs. The pig batches included in the study were placed in lairage pens that were previously sampled, and these were the first slaughtered batches of the day. Immediately after evisceration, the intestines from the tattooed pigs (24 per herd) were removed and identified. Mesenteric lymph nodes were removed, and then placed in a plastic bag kept in a cooler with ice. Twenty-four hours after chilling, the tattooed carcasses were swabbed at three $100 \mathrm{~cm}^{2}$-areas (sternum, hind leg close to the tail, and jaw). Carcass swabs taken from the three areas were pooled and processed as one sample. Additionally, subiliac and prescapular lymph nodes, as well as surface swabs of carcasses before chilling were taken in a sample subset of 10 pigs per herd.

\subsection{Bacteriological analysis}

The carcass swabs, pen and lairage floor samples, as well as $25 \mathrm{~g}$ of feces or lymph nodes were pre-enriched in $225 \mathrm{ml}$ of buffered peptone water (BPW, Merck \& Co., Inc., Whitehouse Station, N.J., U.S.A.) for $24 \mathrm{~h}$ at $37^{\circ} \mathrm{C}$. The lymph node surface was decontaminated by flaming, and $25 \mathrm{~g}$ were taken aseptically and homogenized in a Stomacher (Interscience, St. Nom, France) for $1 \mathrm{~min}$. For the selective enrichment, $100 \mu \mathrm{l}$ and $1 \mathrm{ml}$ of pre-enriched broth were added to $9.9 \mathrm{ml}$ of Rappaport-Vassiliadis (RV, Merck \& Co., Inc.) and $9 \mathrm{ml}$ of Tetrathionate Müller Kauffmann broths (TMK, Difco Laboratories, Detroit, USA), respectively, which were then incubated for $24 \mathrm{~h}$ at $42{ }^{\circ} \mathrm{C}$. Afterwards, a loopful of each enriched broth was streaked onto Xylose-Lysine-Tergitol 4 (XLT4, Difco) and Brilliant-Green Phenol Red Lactose Sucrose (BPLS, Merck) agars. Four presumptive colonies were streaked onto Tryptic Soy Agar (TSA, Merck) and subjected to biochemical tests, including Lysine-Iron agar (LIA, Merck), Urea broth, Phenylalanine agar (Merck), Simmons citrate agar (Merck), $\beta$-galactosidase test (ONPG, Merck), and Triple Sugar-Iron agar (TSI, Merck). SIM Agar (Merck) was used to confirm the Salmonella suspected colonies. A slide agglutination test was performed using polyclonal Salmonella enterica antiserum (Probac Ltda., São Paulo, Brazil). Each Salmonella spp. isolate was serotyped at the National Reference Center, Instituto Oswaldo Cruz, Rio de Janeiro, Brazil. All confirmed Salmonella strains were included in the current study.

\subsection{PFGE of Salmonella isolates and data analysis}

The bacterial suspension was embedded in agarose, lysed, washed, and digested with the restriction enzyme, $\mathrm{XbaI}$ (New England Biolabs, Beverly, MA) overnight (12-16 h) at $37^{\circ} \mathrm{C}$ essentially as described in 
the Centers for Disease Control and Prevention (Atlanta, GA) "OneDay" (24-28 h) Standardized Laboratory Protocol for Molecular Subtyping of Escherichia coli 0157:H7, non-typhoidal Salmonella serotypes, and Shigella sonnei by pulsed field gel electrophoresis (PFGE) (CDC, 2004 http://www.cdc.gov/pulsenet/protocols.htm) (Ribot et al., 2006). Electrophoresis was performed in a 1\% agarose gel using $0.5 \times$ Tris-borate-EDTA buffer on a Chef Mapper XA (BioRad Laboratories, Hercules, CA) at $6 \mathrm{~V} / \mathrm{cm}$ for $19 \mathrm{~h}$ at $14{ }^{\circ} \mathrm{C}$ with an initial switch time of $2 \mathrm{~min}$ and $16 \mathrm{~s}$ and a final switch time of $63.8 \mathrm{~s}$. Gels were stained for $30 \mathrm{~min}$ at room temperature with ethidium bromide (Invitrogen, Carlsbad, CA), destained, and photographed. Salmonella choleraesuis subspecies Braenderup (ATCC\# BAA-664) was included as a reference. Pattern images were acquired using a BioRad Gel Doc system with the Multi-Analyst software program (Bio-Rad; v. 1.1) and analyzed using the Bionumerics software program, Version 2.0 (Applied Maths BVBA, Saint-Martens-Latem-Belgium). Similarities between isolate fingerprints were determined on the basis of the Dice correlation coefficient. A band position tolerance of $1.7 \%$ was used for the analysis of PFGE patterns (Carriço et al., 2005). Dendrograms were generated by unweighted pairwise grouping with mathematical averaging (UPGMA). Isolates were considered as having the same pulsotype when the number and location of the bands were indistinguishable. Isolates with one band difference were considered to be of distinct pulsotypes.

\subsection{Serology}

Blood samples were individually submitted to an ELISA test for detection of IgG-antibodies against the lipopolysaccharide antigen from serovar Typhimurium (Kich et al., 2007). The antigen used for coating the plates was prepared by phenol extraction of a $S$. Typhimurium strain. This serovar belongs to serogroup B and shares at least one somatic antigen (0:12) with serovars of serogroup D1. These two serogroups encompass the most prevalent serovars in southern Brazil (Bessa et al., 2004; Kich et al., 2007).

\subsection{Antimicrobial resistance profile determination}

Antimicrobial resistance profiles (ARP) of Salmonella isolates were determined at the Richard B. Russell Agriculture Research Center (SAA-ARS-USDA, Athens/GA-USA) by the broth microdilution method, validated by Chapin and Musgnug (2003), testing 15 antimicrobials (Sensititre automated antibiotic susceptibility system - Trek Diagnostic Systems Limited, Weslake, $\mathrm{OH}$ ). The antimicrobials tested were amikacin (Ami), amoxicillin/clavulanic acid (Amc), ampicillin (Amp), cefoxitin (Fox), ceftiofur (Cef), ceftriaxone (Axo), cloramphenicol (Chl), ciprofloxacin (Cip), gentamicin (Gen), kanamycin (Kan), nalidixic acid (Nal), streptomycin (Str), sulfamethoxazole/ sulfizoxazole (Sul), tetracycline (Tet) and trimethoprim/sulfametoxazole (Sxt).

\subsection{Statistical analysis}

The prevalence and distribution data were analyzed using the SAS Statistical Package (SAS®, 2003). Multiple correspondence analyses (MCA) were performed using Système Pour Analyse de Données (SPADN®, 1998) resources to group the Salmonella pulsotypes from different samples. The MCA is a multivariate technique used to examine, describe, and summarize the geometric relations of qualitative variables. This structure is represented graphically and does not require fundamental distributions (Greenacre, 1984). The MCA, like dendrograms, are descriptive and do not include formal statistical testing. The use of MCA in the field of microbial ecology has been recently reviewed and advocated (Ramette, 2007; Ravel et al., 2009).

To achieve the MCA, data were processed to identify all of the pulsotypes present in the herds and from then on to identify the presence or absence of each pulsotype in the different types of samples. These data were tabulated, and the origin of the samples was linked to the presence or absence of the isolated Salmonella pulsotypes. Antimicrobial resistance profiles (ARP) were analyzed by descriptive statistic, and the association with pulsotypes was tested by $\chi^{2}$. For the association analysis of ARP, pulsotypes, and sample origin, pulsotypes consisted of at least 10 isolates and ARPs occurring in at least five isolates of these pulsotypes were submitted to MCA. Discrimination measures and variables with test values above 2 in at least one factor were deemed statistically significant and kept in the analyses.

\section{Results}

On placement day (70-day-old pigs), the seroprevalence was $23 \%$ (ranging from 0 to 66\%) and increased to $92 \%$ (83 to 100\%) at the slaughter age (150-day-old pigs), demonstrating the exposure to Salmonella in all herds. Analysis of 1258 samples from twelve finishing herds, including those taken at the slaughterhouse revealed that 487 samples (39\%) were positive for Salmonella. The distribution of positive samples among the 12 herds is shown in Table 1 . Overall Salmonella was most found in swabs taken from the lairage floor (90\%) and mesenteric lymph nodes (67\%), yielding a total of 1255 isolated strains. Salmonella isolates submitted for serotyping $(\mathrm{n}=1158)$ were distributed as follows: Typhimurium (50.7\%); Panama (28.5\%); Derby (6.3\%); Senftenberg (5.4\%); Mbandaka (4.6\%); Infantis (1.5\%); Houtenae (0.7\%); Montevideo (0.5\%) and Salmonella sp. (1.9\%).

A total of 1071 isolates were clustered in 163 pulsotypes by PFGE analysis. Ninety-three pulsotypes were observed only once, and 50 pulsotypes were less frequent, including five isolates or less. Isolates $(\mathrm{n}=324$ ) originating from the same sample belonging to a common pulsotype were considered duplicates and excluded from further analysis.

The highest number of isolates and pulsotypes was obtained from the mesenteric lymph nodes; however, the largest variability among pulsotypes was observed in isolates from the finishing herd pen floors, carcass surfaces before chilling, and lairage with isolates/ pulsotype ratios of $1.4,1.5$ and 1.9 , respectively (Table 2).

Multiple correspondence analyses of isolates clustered according to their Xbal pulsotypes and sample origin, considering all herds together, is presented in Fig. 1. The right side of the map (A) shows the relationship among isolates from shedder pigs (feces), herd environment (pen floors), and subiliac and prescapular lymph nodes. In the lower left region, the association between isolates originating from lairage and carcass surface samples is depicted. In this analysis,

Table 1

Distribution of Salmonella positive samples and the number of strains recovered from different types of samples from 12 swine finishing herds and a slaughter facility.

\begin{tabular}{|c|c|c|c|c|c|}
\hline & \multicolumn{3}{|c|}{ Samples } & \multirow{2}{*}{$\frac{\text { Isolates }}{\mathrm{N}}$} & \multirow[t]{2}{*}{${ }^{1}$ Serovar } \\
\hline & $\mathrm{N}$ & Positive & $\%$ & & \\
\hline Herd pen floors & 61 & 16 & 26 & 31 & $\mathrm{Tp}, \mathrm{Pm}, \mathrm{Db}, \mathrm{Ss}$ \\
\hline Feces & 178 & 87 & 49 & 193 & Tp,Pm,Db,Ht \\
\hline Lairage & 40 & 36 & 90 & 102 & $\mathrm{Tp}, \mathrm{Pm}, \mathrm{Db}, \mathrm{Mb}, \mathrm{Sf}, \mathrm{In}, \mathrm{Ss}$ \\
\hline Feed & 143 & 42 & 29 & 180 & Tp,Pm,Mb,Sf, Md \\
\hline Mesenteric lymph nodes & 278 & 186 & 67 & 501 & Tp,Pm,Db,Mb,Sf,In,Ht \\
\hline $\begin{array}{l}\text { Carcass surface - } \\
\text { before chilling }\end{array}$ & 98 & 24 & 24 & 72 & $\mathrm{Tp}, \mathrm{Pm}, \mathrm{Db}$ \\
\hline $\begin{array}{l}\text { Carcass surface - } \\
\text { after chilling }\end{array}$ & 260 & 62 & 24 & 114 & $\mathrm{Tp}, \mathrm{Pm}, \mathrm{Db}, \mathrm{Mb}, \mathrm{In}, \mathrm{Ss}$ \\
\hline Subiliac lymph nodes & 100 & 24 & 24 & 42 & $\mathrm{Tp}, \mathrm{Pm}$ \\
\hline Prescapular lymph nodes & 100 & 11 & 11 & 21 & Tp,Pm,Db,Mb \\
\hline Total & 1258 & 487 & 39 & 1255 & \\
\hline
\end{tabular}

$1 \mathrm{Tp}=$ Typhimurium, Pm = Panama, Db = Derby, $\mathrm{Mb}=$ Mbandaka, Sf = Senftenberg, In = Infantis, $\mathrm{Md}=$ Montevideo, $\mathrm{Ht}=$ Houtenae, $\mathrm{Se}=$ Salmonella $\mathrm{sp}$. 
Table 2

Distribution of Salmonella isolated among Xbal pulsotypes according to the origin of samples taken in 12 finishing swine herds in one slaughter facility in Southern Brasil.

\begin{tabular}{|c|c|c|c|}
\hline \multirow[t]{2}{*}{ Sample origins } & \multirow{2}{*}{$\frac{\text { Isolates }}{\mathrm{N}}$} & \multirow{2}{*}{$\frac{\text { Pulsotypes }}{\mathrm{N}}$} & \multirow{2}{*}{$\begin{array}{l}\text { Ratio isolates/ } \\
\text { pulsotype }\end{array}$} \\
\hline & & & \\
\hline Mesenteric lymph nodes & 290 & 73 & 3.9 \\
\hline Feces and pooled feces & 122 & 39 & 3.1 \\
\hline Feed & 80 & 30 & 2.7 \\
\hline Lairage & 78 & 41 & 1.9 \\
\hline Carcass surface - after chilling & 75 & 27 & 2.78 \\
\hline Carcass surface - before chilling & 41 & 28 & 1.5 \\
\hline Subiliac lymph nodes & 30 & 13 & 2.3 \\
\hline Herd pen floors & 20 & 14 & 1.4 \\
\hline Prescapular lymph nodes & 11 & 5 & 2.2 \\
\hline Total & 747 & & \\
\hline
\end{tabular}

feed isolates appear as outliers in the map, showing a low correlation with the other isolates.

The dendrogram constructed with the 20 most prevalent XbaI pulsotypes showed a similarity coefficient ranging from 75 to $95 \%$ (Fig. 2). These pulsotypes encompassed 505 strains belonging to serovars Typhimurium, Panama, Derby, Senftenberg, Mbandaka, and Infantis. Pulsotype 32 clustered the highest number of strains (136 $S$. Typhimurium isolates) and was found in all herds and sample types. Isolates recovered from mesenteric lymph nodes, carcass and lairage were represented in nineteen, fifteen and twelve of the 20most prevalent pulsotypes.

One isolate per serovar recovered from each sample was submitted to antimicrobial resistance testing. From the total number $(n=572)$ of strains, $17 \%(n=97)$ were susceptible to all 15 tested antimicrobials, and $83 \%(n=475)$ were resistant to at least one of them. Resistance was observed against: tetracycline (79\%), ampicillin (46\%), kanamycin (41\%), gentamicin (39\%), streptomycin (35\%), sulfamethoxazole/sulfizoxazole (23\%), trimethoprim/sulfamethoxazole $(10 \%)$, cloramphenicol (10\%), cephalothin (5\%), nalidixic acid (5\%), amoxicillin/clavulanic acid (1\%), and cefoxitin (1\%). No strains showed resistance against amikacin, ceftiofur, ceftriaxone, and ciprofloxacin. Multi-resistance (resistance against at least four antimicrobials) was observed in $43 \%(n=246)$ of the tested strains. A total of 59 antimicrobial resistance profiles (ARP) were identified, and those ARPs were significantly $(\mathrm{P}<0.0001)$ associated with $\mathrm{Xbal}$ pulsotypes. The AmpGenKanTet profile was the most prevalent and was identified in 138 isolates of $S$. Typhimurium (pulsotypes 32, 33, and 34) and one isolate of S. Panama (pulsotype 127).

The output from the MCA clustering of 332 most frequent Salmonella strains according to pulsotypes, ARP, and isolation origin is depicted in Fig. 3. According to the association of the three tested variables, five clusters (A-E) were formed as follows. The right side of the map (A) clustered three pulsotypes $(32,33$, and 34) of serovar Typhimurium detected in feces and carcass samples with two ARPs (AmpGenKanTet and AmpGenKanSulTet). Cluster B was composed of S. Derby (P76) isolated from the pen floor with the StrSulTet profile. Three pulsotypes (P125, P127, and P134) of S. Panama were associated with three ARPs (Tet, StrTet, and GenStrTet) in region C of the map. The multi-resistance profile AmpGenStrSulTetTri was clustered with $S$. Senftenberg isolated from feed (sub-region C1). Cluster D resulted from the association of the NalTet profile, $S$. Mbandaka pulsotype 14 and prescapular lymph nodes. S. Typhimurium pulsotypes P38 and P39 were clustered with AmpTet and susceptible profiles and the origin was mesenteric lymph nodes (region E).

\section{Discussion}

In Brazil, a number of studies have shown that the finishing step is responsible for enhancing Salmonella-transmission and delivery of pig batches with a high number of carriers at slaughterhouses (Bessa et al., 2004; Kich et al., 2007; Schwarz et al., 2009). The same scenario was observed in our study, since twelve cohorts of pigs, with a low seroprevalence at placement on the farm and followed throughout the finishing phase, presented an increase in the number of Salmonella-seropositive pigs. Dominant clonal groups were widely distributed among herds, feed, lairage, pigs, and carcasses. All sampled herds received feed from the same feed mill, and the pigs were delivered to the same slaughterhouse. Isolation of Salmonella from pen floors and pig feces on the placement day, as well as from feed batches delivered at the farms demonstrated that all these sources may have contributed to Salmonella transmission.

Multiple infection sources were also reflected in the distribution of Salmonella serovars. The three most frequent serovars (Typhimurium, Panama, and Derby) were found in samples originating from the farm (pen floor, feed, and feces) and those taken at slaughter (lairage, lymph nodes, and carcasses). In our study, the genetic variability among the isolates was demonstrated by the high number of Xbal pulsotypes and by the ratio of isolates per pulsotype (Table 2).

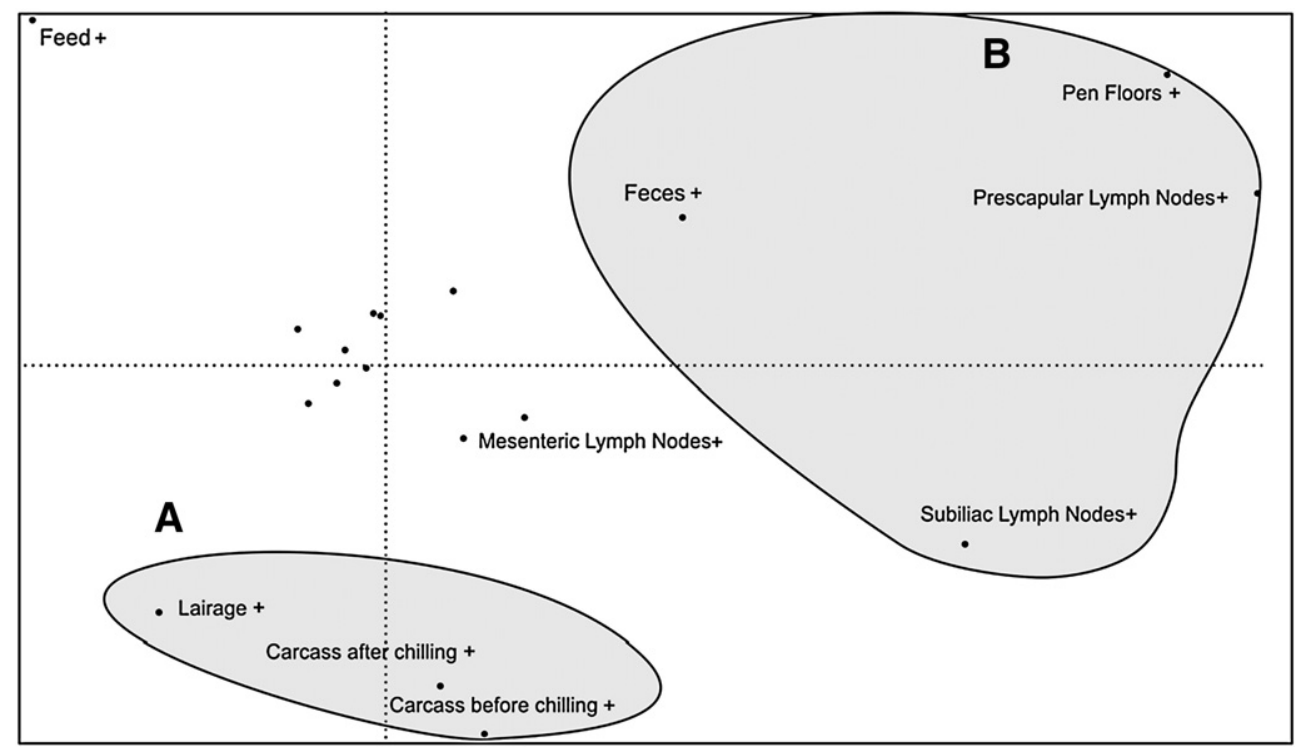

Fig. 1. Map of multiple correspondence analyses of 747 porcine Salmonella isolates clustered according XbaI pulsotypes and sample origin. 

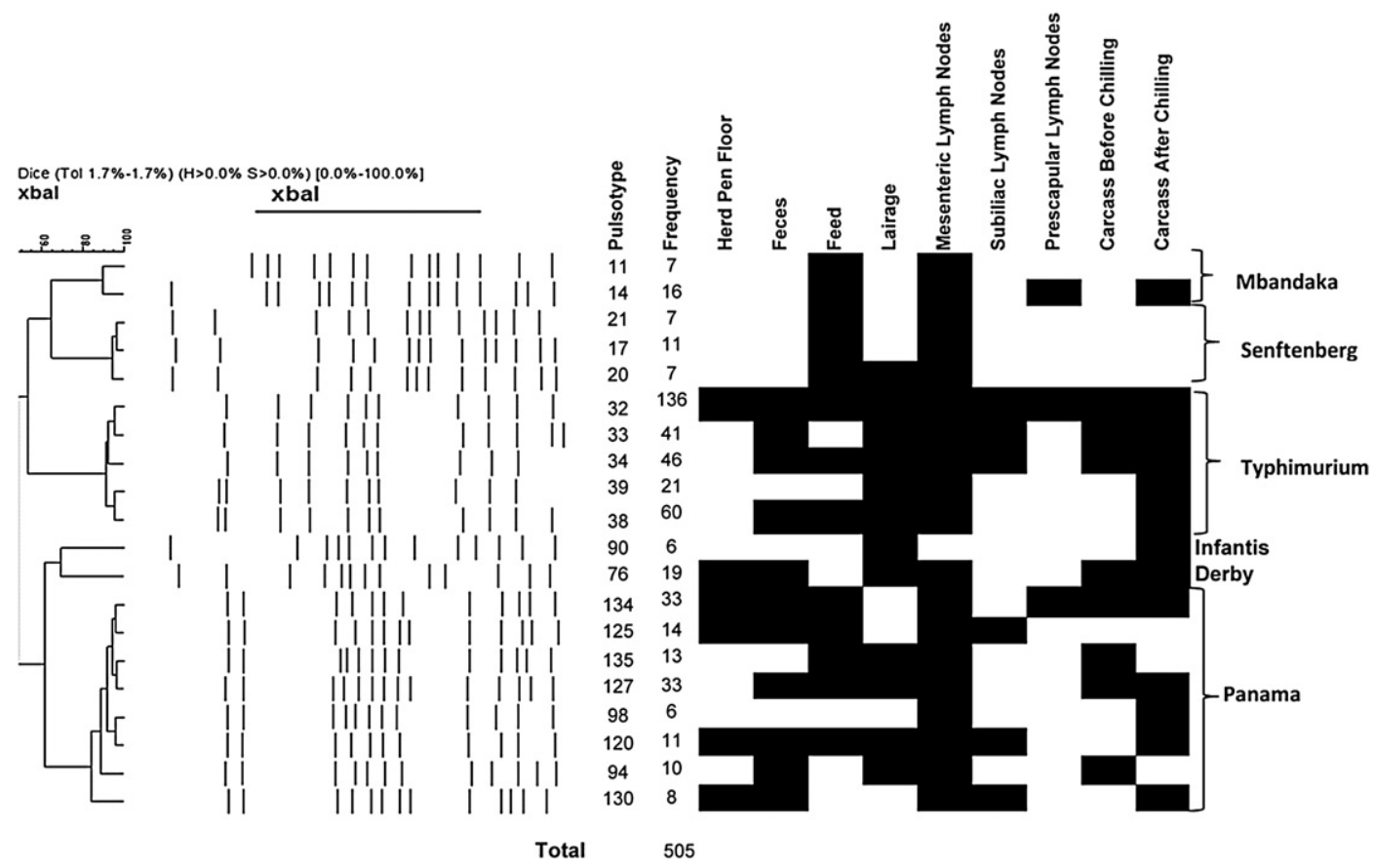

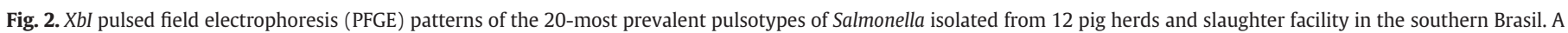
black box indicates in what sample the pulsotype was detected.

Among the samples, those taken from the environment (herd pen floor and lairage) presented the largest pulsotype variability, possibly due to the persistence of strains excreted by many carrier pigs over time.

Pulsotypes found in the herd environment and feces collected at placement day were clustered together with pulsotypes from deep lymph nodes (prescapular and subiliac - Fig. 1). In this case, the transmission time may explain the observed association, since the 80-day period between placement in a contaminated facility and slaughter may have been enough for Salmonella to reach deep lymph nodes by the lymphatic pathway. However, the largest number of isolates (290) and the majority (19 out 20) of the most frequent pulsotypes were found in the mesenteric lymph nodes
(Fig. 2). Salmonella is transmitted to pigs mostly by the fecal-oral route and can survive inside lymphocytes for long periods (Boyen et al., 2008). Thus, Salmonella found inside the mesenteric lymph nodes probably originated from multiple contaminated sources that the pigs contacted throughout their lives.

One of the sources implicated in high Salmonella herd prevalence is contaminated feed (Österberg et al., 2006; Molla et al., 2010). In our study $29 \%$ of the feed samples were Salmonella positive, and thirteen of the most common pulsotypes were found in feed, as well as in feces, mesenteric lymph nodes, lairage, and carcasses (Fig. 2). However, a correspondence between feed and carcass pulsotypes was not demonstrated in the MCA (Fig. 1). The high association (33 out of 40 isolates) of serovar Senftenberg with feed samples may have

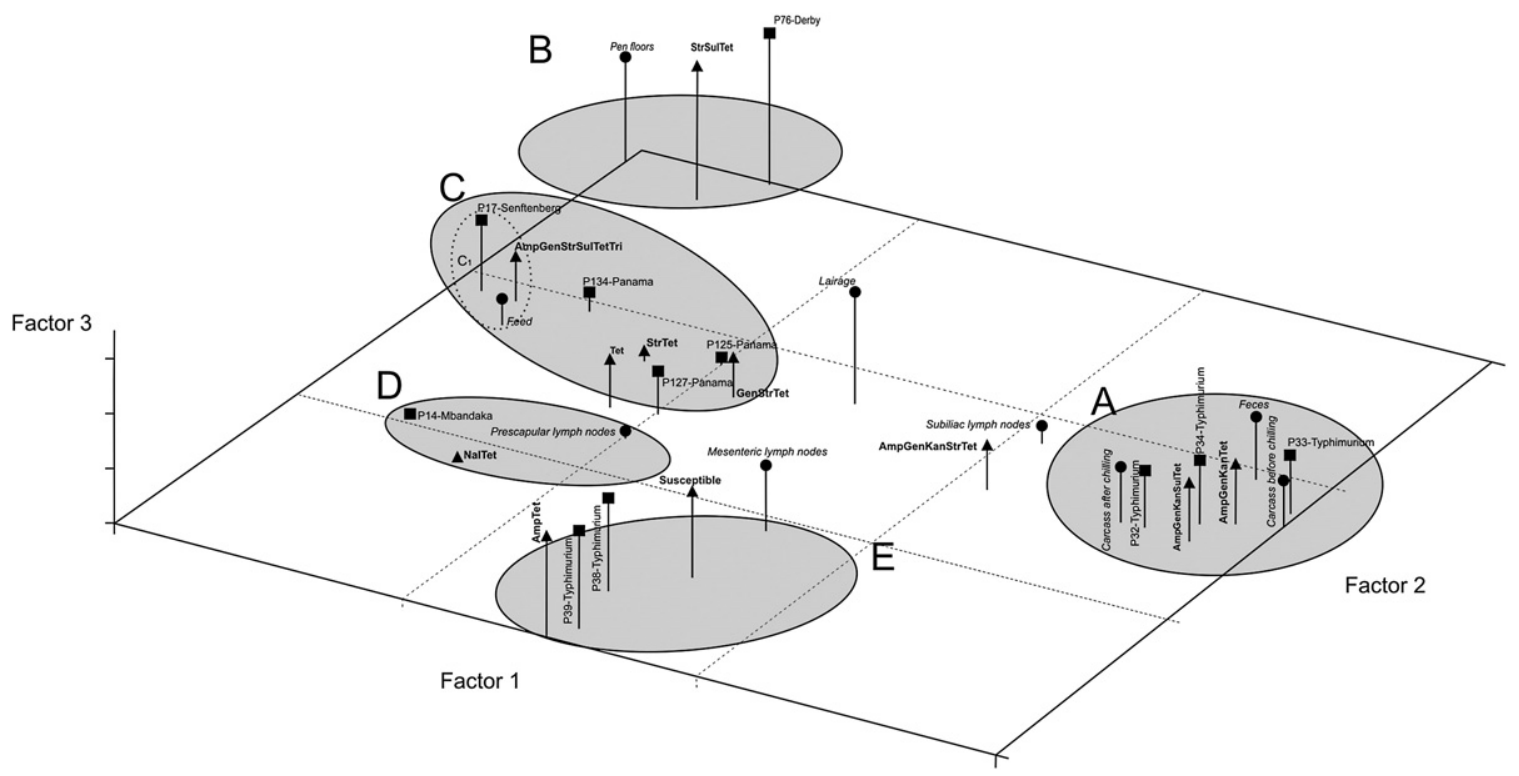

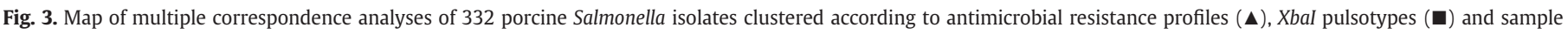
origin (๑) 
determined the formation of a cluster encompassing only feed isolates (Fig. 1), which was unrelated to other profiles. S. Senftenberg is an important feed-related serovar, and it has been frequently isolated from feed, feed ingredients, and environmental samples taken in farms and feed factories (Bailey et al., 2001; Nesse et al., 2003; Pedersen et al., 2008; Papadopoulou et al., 2009). Berends et al. (1996) estimated that about $15-30 \%$ of all infections in the finishing period were attributed to contaminated feed and that carrier pigs were the most important source of carcass contamination; however, the association between feed and pork contamination is not yet clear.

A high variability was found among isolates from carcasses before chilling, and MCA of Xbal-pulsotypes showed that they were more closely related to lairage isolates than to any other group of strains (Fig. 1). The continuous delivery of carrier batches leads to a high level of Salmonella in the lairage environment and makes total disinfection highly difficult at the end of the slaughter day. Moreover, cleaning and disinfection of drinkers are particularly challenging due to the accumulation of organic matter in the crevices, which protects Salmonella from chemical agents and contributes to the residual contamination (Mannion et al., 2007). Additionally, the six hour holding period demanded by Brazilian swine slaughter policy is far greater than the time required for Salmonella intestinal invasion (Hurd et al., 2001a). Consequently, a high number of pigs, placed in those residual contaminated lairage pens, may have entered in the slaughter line carrying Salmonella in the gut, as demonstrated in other studies (Hurd et al., 2001b; Vieira-Pinto et al., 2006; De Busser et al., 2011). In spite of the fact that all batches presented a high number of Salmonella carrier pigs at the end of the finishing period, isolates originated from lairage proved to be the most important source of carcass surface contamination in our study.

Another concern emerging in recent years is related to food-borne pathogens harboring antimicrobial resistance genes. In a previous study, porcine Salmonella isolates displayed the highest rate of resistance among strains isolated from various animal species (Zhao et al., 2005), highlighting the importance of monitoring pork isolates. In the current study, $83 \%$ of the tested isolates were resistant to at least one antimicrobial, and multi-resistance (resistance to three or more classes of antibiotics) occurred in $43 \%$ of the isolates. The important MDR profile, ACSSuT (ampicillin, chloramphenicol, streptomycin, sulfizoxazole and tetracycline), found in porcine Salmonella isolates in many countries, occurred only once in our study, in agreement with previous studies that failed to identify this resistance pattern in the same region (Bessa et al., 2007; Michael et al., 2008).

The most frequently identified MDR profile was AmpGenKanTet, which was identified in all types of samples. This profile was more associated to pulsotypes 32, 33, and 34 of $S$. Typhimurium isolated from carcass surface samples (Fig. 3). Moreover, in isolates from pulsotype 32, the aforementioned MDR profile, resistance against sulfamethoxazole/sulfizoxazole (AmpGenKanSulTet) was also detected. Both MDR profiles are clustered together with a common origin (carcass and feces) in the MCA map, indicating that these profiles were highly prevalent in carcass samples, and the isolates may have originated from the farm. The spread of multidrug-resistant Salmonella is a function of successful clonal expansion, because the majority of resistance determinants are clearly associated with mobile genetic elements (Butaye et al., 2006) and with extensive antibiotic use on the farm (Threlfall et al., 2000). This hypothesis may explain our results, since both resistance profiles include antimicrobials routinely used in swine production in Brazil. On the other hand, the MDR profile harboring the greatest number of resistance markers (AmpGenStrSulTetTri) was clustered only with $S$. Senftenberg from feed samples. S. Senftenberg is considered more resistant to stress than other serovars (Lui et al., 1969; Pedersen et al., 2008; Alvarez-Ordonez et al., 2010) and harbors plasmidial resistance genes that may contribute to the spread of the multi-resistance pattern (Veldman et al., 2010).
In conclusion, this study demonstrated the relationship of Salmonella clonal groups originating from various steps of a vertical swine production system to carcass contamination. Clonal groups associated to the farm environment and feces were found in lymph nodes but were less associated with carcass strains, while lairage strains were highly prevalent on pre-chill and post-chill carcasses. On the contrary, multiresistant (AmpGenKanTet) S. Typhimurium strains found on carcasses mostly originated from farm samples. Thus, strains harbored by pigs themselves constitute a minor origin of carcass contamination, although such strains reaching the carcass may represent a major hazard for consumers. These results highlight that an integrated Salmonella control program based on pre-harvest good management practices on the farm, prudent use of antimicrobials, disinfection of the lairage environment, and hazard analysis and control of critical point systems at slaughter should be implemented to decrease the hazard of Salmonella transmission to consumers.

\section{Acknowledgments}

We thank Jovita Haro at the Agricultural Research Service (ARS), Richard B. Russell Research Center, for performing the antimicrobial resistance tests. We are also grateful to Embrapa and the ARS, Eastern Regional Research Center for funding this study.

\section{References}

ABIPECS, 2007. Brazilian Pork Industry and Exporter Association. Relatorio Annual - 2007. http://www.abipecs.org.br/uploads/relatorios/relatorios-associados/ ABIPECS_relatorio_2007_pt.pdf. Accessed 02/22/2011.

ABIPECS, 2010. Brazilian Pork Industry and Exporter Association. Annual Report - year 2009-2010. http://www.abipecs.org.br/uploads/relatorios/relatorios-associados-ingles/ Abipecs_Annual_Report_2009.pdf. Accessed 02/22/2011.

Alvarez-Ordonez, A., Fernandez, A., Bernardo, A., Lopez, M., 2010. Acid tolerance in Salmonella typhimurium induced by culturing in the presence of organic acids at different growth temperatures. Food Microbiology 27, 44-49.

Bailey, J.S., Stern, N.J., Fedorka-Cray, P., Craven, S.E., Cox, N.A., Cosby, D.E., Ladely, S., Musgrove, M.T., 2001. Sources and movement of Salmonella through integrated poultry operations: a multistate epidemiological investigation. Journal of Food Protection 64 (11), 1690-1697.

Bean, N.H., Griffin, P.M., 1990. Foodborne disease outbreaks in United States. 1973-87: pathogens, vehicles and trends. Journal of Food Protection 53, 804-817.

Berends, B.R., Urlings, H.A., Snijders, J.M., Van Knapen, F., 1996. Identification and quantification of risk factors in animal management and transport regarding Salmonella spp. in pigs. International Journal of Food Microbiology 30, 37-53.

Berends, B.R., Van Knapen, F., Snijders, J.M., Mossel, D.A., 1997. Identification and quantification of risk factors regarding Salmonella spp. on pork carcasses. International Journal of Food Microbiology 36, 199-206.

Bessa, M.C., Costa, M., Cardoso, M., 2004. Prevalência de Salmonella sp. em suínos abatidos em frigoríficos do Rio Grande do Sul. Pesquisa Veterinária Brasileira 24 80-84.

Bessa, M.C., Michael, G.B., Canu, N., Canal, C., Cardoso, M., Rabsch, W., Rubino, S., 2007 Phenotypic and genetic characterization of Salmonella enterica subsp. enterica serovar Typhimurium isolated from pigs in Rio Grande do Sul, Brazil. Research Veterinary Science 83, 302-310.

Blas, N., de Ortega, C., Flankena, K., Noordhuizen, K., Thrusfield, M., I. Win Episcope 2.0, EPIDECON, Borland ${ }^{\circledR}$ y Delphi ${ }^{\mathrm{TM}}$ Online. Available: http://www.clive.ed.ac.ed/ winepiscope/ Accessed 12/.17/.2007.

Borch, E., Nesbaskken, T., Christensen, H., 1996. Hazard identification in swine slaughter with respect to foodborne bacteria. International Journal of Food Microbiology 30, 9-25.

Botteldoorn, N., Herman, L., Rijpens, N., Heyndrickx, M., 2004. Phenotypic and molecular typing of Salmonella strains reveals different contamination sources in two commercial pig slaughterhouses. Applied and Environmental Microbiology 70, 5305-5314

Boyen, F., Haesebrouck, F., Maes, D., van Immerseel, F., Ducatelle, R., Pasmans, F., 2008 Non-typhoidal Salmonella infections in pigs: a closer look at epidemiology, pathogenesis and control. Veterinary Microbiology 130, 1-19.

Butaye, P., Michael, G.B., Schwarz, S., Barrett, T.J., Brisabois, A., White, D.J., 2006. The clonal spread of multidrug-resistant non-typhi Salmonella serotypes. Microbes and Infection 8, 1891-1897.

Carriço, J.A., Pinto, F.R., Simas, C., Nunes, S., Sousa, N.G., Franzão, N., de Lencastre, H. Almeida, J.S., 2005. Assessment of band-based similarity coefficients for automatic type and subtype classification of microbial isolates analyzed by pulsed-field gel electrophoresis. Journal of Clinical Microbiology 43, 5483-5490.

CDC. Center for Disease Control and Prevention, 2004. Fact Sheet: Foodborne llness. http://www.cdc.gov/pulsenet/protocols/campy_protocol.pdf. Accessed 02/22/2011. 
CDC. Center for Disease Control and Prevention, 2008. Annual Report. http://www.cdc. gov/narms/annual/2008/narms_2008_annual_report.pdf. Accessed 02./22/2011.

Chapin, C.K., Musgnug, M.C., 2003. Validation of the automated reading and incubation system with sensititre plates for antimicrobial susceptibility testing. Journal of Clinical Microbiology 41, 1951-1956.

De Busser, E.V., Maes, D., Houf, K., Dewulf, J., Imberechts, H., Bertrand, S., De Zutter, L., 2011. Detection and characterization of Salmonella in lairage, on pig carcasses and intestines in five slaughterhouses. International Journal of food Microbiology 1145 279-286.

Duijkeren, E., Wannet, W.J.B., Houwers, D.J., Pelt, W., 2003. Antimicrobial susceptibilities of Salmonella strains isolated from humans, cattle, pigs and chickens in The Netherlands from 1984 to 2001. Journal of Clinical Microbiology 41, 3574-3578.

Funk, J.A., Davies, P.R., Nichols, M.A., 2001. Longitudinal study of Salmonella enterica in growing pigs reared in multiple-site swine production systems. Veterinary Microbiology 83, 45-60.

Giovannacci, I., Queguiner, S., Ragimbeau, C., Salvat, G., Vendeuvre, J.L., Carlier, V., Ermel, G., 2001. Tracing of Salmonella spp. in two pork slaughter and cutting plants using serotyping and macrorestriction genotyping. Journal of Applied Microbiology 90, 131-147.

Greenacre, M.J., 1984. Theory and applications of correspondence analysis. Academic Press, London.

Hurd, H.S., Gailey, J.K., Mckean, J., Rostagno, M.H., 2001a. Rapid infection in marketweight swine following exposure to a Salmonella Typhimurium-contaminated environment. Applied and Environmental Microbiology 62, 1194-1197.

Hurd, H.S., Mckean, J.D., Wesley, I.V., Karriker, L.A., 2001b. The effect of lairage on Salmonella isolation from market swine. Journal Food Protection 64, 939-944.

IBGE, 2011. http://www.ibge.gov.br/home/estatistica/indicadores/agropecuaria/ producaoagropecuaria/abate-leite-couro-ovos_201004_publ_completa.pdf. Accessed 02/22/2011.

Kich, J.D., Schwarz, P., Silva, L.E., Coldebella, A., Piffer, I.A., Vizzotto, R., Cardoso, M.R.I.C., 2007. Development and application of an enzyme-linked immunosorbent assay to detect antibodies against prevalent Salmonella serovars in swine in southern Brazil. Journal of Veterinary Diagnostic Investigation 19, 510-517.

Lui, T.S., Snoeyenbos, G.H., Carlson, V.L., 1969. Thermal resistance of Salmonella senftenberg 775W in dry animal feeds. Avian Diseases 13 (3), 611-631.

Mannion, C., Lvnch, P.B., Egan, J., Leonard, F.C., 2007. Efficacy of cleaning and disinfection on pig farms in Ireland. The Veterinary Record 161, 371-375.

Michael, G.B., Cardoso, M., Schwarz, S., 2005a. Class1 integron-associated gene cassettes in Salmonella enterica subsp. enterica serovar Agona isolated from pig carcasses in Brazilian. Journal Antimicrobial Chemotherapy 55, 776-779.

Michael, G.B., Cardoso, M., Schwarz, S., 2005b. Identification of an aadA2 gene cassette in Salmonella enterica subsp. enterica serovar Derby. Journal of Veterinary Medicine $52,456-459$.

Michael, G.B., Cardoso, M., Schwarz, S., 2008. Molecular analysis of multiresistant porcine Salmonella enterica subsp. enterica serovar Bredeney isolates from Southern Brazil: identification of resistance genes, integrons and a group II intron. International Journal of Antimicrobial Agents 32, 120-129.

Molla, B., Sterman, A., Mathews, J., Artuso-Ponte, V., Abley, M., Farmer, W., Rajala-Schultz, P., Morrow, W.E.M., Gebrayes, W., 2010. Salmonella enteric in commercial swine feed and subsequent isolation of phenotypically and genotypically related strains from fecal samples. Applied and Environmental Microbiology 76, 7188-7193.

Nesse, L.L., Nordby, K., Heir, E., Bergsjoe, B., Vardund, T., Nygaard, H., Holstad, G., 2003. Molecular analyses of Salmonella enterica isolates from fish feed factories and fish feed ingredients. Applied and Environmental Microbiology 69 (2), 1075-1081.

Österberg, J., Vågsholm, I., Boqvist, S., Lewerin, S.S., 2006. Feed-borne outbreak of Salmonella Cubana in Swedish pig farms: risk factors and factors affecting the restriction period in infected farms. Acta Veterinaria Scandinavica 47, 13-22.

Papadopoulou, C., Carrique-Mas, J.J., Davies, R.H., Sayers, A.R., 2009. Retrospective analysis of Salmonella isolates recovered from animal feed in Great Britain. Veterinary Record 165, 681-688.
Pedersen, T.B., Olsen, J.E., Bisgaard, M., 2008. Persistence of Salmonella Senftenberg in poultry production environments and investigation of its resistance to desiccation. Avian Pathology 37 (4), 421-427.

Ramette, A., 2007. Multivariate analyses in microbial ecology. FEMS Microbiology Ecology 62, 142-160.

Ravel, A., Greig, J., Tinga, C., Todd, E., Campbell, G., Cassidy, M., Marshall, B., Pollari, F., 2009. Exploring historical Canadian foodborne outbreak data sets for human illness attribution. Journal of Food Protection 72, 1963-1976.

Ribot, E.M., Fair, M.A., Gautom, R., Cameron, D.N., Hunter, S.B., Swaminathan, B., Barrett, T.J., 2006. Standardization of pulsed-field gel electrophoresis protocols for subtyping of Escherichia coli 0157:H7, Salmonella, and Shigella for PulseNet. Foodborne Pathogens and Disease 3, 59-67.

SAS®. Statistical Package Software: System for Microsoft Windows: release 9.1.3. Inc., 2002-2003. 1 CD-ROM. SAS Institute Inc., 100 SAS Campus Drive, Cary, USA. NC 27513-2414.

Schwarz, P., Calveyra, J., Sella, A., Bessa, M.C., Cardoso, M.R.I., 2009. Salmonella enterica: soroprevalência e isolamento em suínos abatidos no Rio Grande do Sul. Arquivo Brasileiro de Medicina Veterinária e Zootecnia 61, 1028-1034.

Silva, L.E., Gotardi, C.P., Vizzotto, R., Kich, J.D., Cardoso, M.R.I., 2006. Infecção por Salmonella enterica em suínos criados em um sistema integrado de produção do sul do Brasil. Arquivo Brasileiro de Medicina Veterinária e Zootecnia 58, $455-461$.

SPAND®, 1998. Data Quality Management. SPADN® version 3.7. SPAD 22, Quai Gallieni, 92150, Suresnes, France.

Threlfall, E.J., Ward, L.R., Frost, J.A., Cheasty, T., Geraldine, A., Willshaw, G.A., 2000. The emergence and spread of antibiotic resistance in food-borne bacteria. International Journal of Food Microbiology 62, 1-5.

Trobos, M., Lester, C.H., Olsen, J.E., Frimodt-Møller, N., Hammerum, A.M., 2008. Natural transfer of sulphonamide and ampicillin resistance between Escherichia coli residing in the human intestine. Journal of Antimicrobial Chemotherapy 63, 80-86.

Veldman, K., Dierikx, C., van Essen-Zandbergen, A., van Pelt, W., Mevius, D., 2010. Characterization of multidrug-resistant, qnrB2-positive and extended-spectrum-b-lactamaseproducing Salmonella Concord and Salmonella Senftenberg isolates. Journal of Antimicrobial Chemotherapy 65, 872-875.

Vieira-Pinto, M., Tenreiro, R., Martins, C., 2006. Unveiling contamination sources and dissemination routes of Salmonella sp. SP. I in pigs at a Portuguese slaughterhouse through macrorestriction profiling by pulsed-fields gel electrophoresis. International Journal of Food Microbiology 110, 77-84.

Vigo, G.B., Cappuccio, J.A., Piñeyro, P.E., Salve, A., Machuca, M.A., Quiroga, M.A., Moredo, F., Giacoboni, G., Cancer, J.L., Caffer, I.G., Binsztein, N., Pichel, M., Perfumo, C.J. 2009. Salmonella enterica subclinical infection: bacteriological, serological, pulsed-field gel electrophoresis, and antimicrobial resistance profiles- longitudinal study in a three-site farrow-to-finish farm. Foodborne Pathogens and Disease 6, 965-972.

Wedel, S.D., Bender, J.B., Leano, F.T., Boxrud, D.J., Hedberg, C., Smith, K.E., 2005. Antimicrobialdrug susceptibility of human and animal Salmonella Typhimurium, Minnesota, 19972003. Emerging Infectious Diseases 11, 1899-1906.

WHO, 2005. World Health Organization. Food Safety and Foodborne illness. Fact Sheet $\mathrm{n}^{\circ} 139$ http://new.paho.org/carec/dmdocuments/8.\%20Food-borne.pdf. Accessed $11 / 19 / 2009$.

Wonderling L, Pearce, R, Wallace, F.M., Call, J.E, Feder, I, Tamplim, M., Luchansky, J. 2003. Use of pulsed-field gel electrophoresis to characterize the heterogeneity and clonality of Salmonella isolates obtained from the carcasses and feces of swine at slaughter. Applied and Environmental Microbiology 69, 4177-4182.

Zhao, S., Fedorka-Cray, P.J., Frieman, S., McDermott, P.F., Walker, R.D., Qaiyumi, Q.A. Foley, S.L., Hubert, S., Ayers, S., English, S., Dargatz, L., Salamone, B., White, D.G., 2005. Characterization of Salmonella Typhimurium of animal origin obtained from the national antimicrobial resistance monitoring system. Foodborne Pathogens and Disease 2, 169-181. 